\title{
The Stall Inceptions in an Axial Compressor with Single Circumferential Groove Casing Treatment at Different Axial Locations
}

\author{
Le Liu, Jichao Li, Xi Nan, Feng Lin \\ Key Laboratory of Advanced Energy and Power, \\ Institute of Engineering Thermophysics, Chinese Academy of Sciences \\ Beijing 100190, China
}

\begin{abstract}
Circumferential groove (CG) casing treatment is known to be a good method to improve the stall margin of axial compressor. Recent studies on single groove indicate the stall margin improvement (SMI) is significantly affected by groove's axial location, which means the effects of the groove on the passage flow should be further studied as the groove's axial location is changed. In this paper the features of stall inception with and without the groove treatment are experimentally researched in a low-speed axial compressor. The contour of static pressure on casing is obtained by fast-response pressure transducers concentrated mounted as a line in chordwise direction, and the data acquired by transducers in circumferential direction is processed with the method of wavelet analysis to demonstrate the development of stall inception. It is found the stall inception is the typically spike-type for smooth casing (without treatment), which is manifested as short-scaled disturbance of only 2-4 blade passages when it appears. Two single grooves at different axial locations, which are ineffective and effective in SMI, are further tested. The results indicate the stall inception is still spike-type for both of them. However, for the ineffective groove, the stall inception is found to be relatively longer-scaled disturbance. For the effective groove, it is still the typical short-scaled disturbance similar to the smooth casing. In the further study on double grooves treatment in which the ineffective groove is included, the stall inception is also found to be relatively longer-scaled type. According to these experimental results and previous CFD simulation, the groove with almost no SMI is believed to take different effects on the compressor which modifies the stall inception into the relatively longer-scaled type, and the corresponding tip-region flow structure deserves more future study in this regard.
\end{abstract}

Keywords: Stall Inception, Wavelet Analysis, Single Circumferential Groove.

\section{Introduction}

Sufficient stall margin is crucial to the safe operation of axial compressors. Many researches have been focused on the methods to improve the stall margin, among which the circumferential groove casing treatment is proved to be a simple and effective method. In previous literatures, much attention has been taken on understanding the mechanism by which the grooves improve the stall margin. It is generally believed the "suctioninjection" effect exists on the two sides of blade due to the groove treatment (Shabbir et al. [1]). In this regard, the change of tip leakage vortex trajectory by grooves is widely discussed, such as the researches by Müller et al. [2,3] and Bennington [4]. The tip leakage flow (TLF) is deflected and the spillage of the interface between tip leakage flow and main flow is then postponed by this effect (Nan et al. [5]), which is deemed as the criteria for the appearance of spike-type stall inception proposed by Vo et al. [6].
In recent years, the single groove has also been widely investigated as it is a direct method to clarify the groove's mechanism at different axial locations, such as Sakuma et al. [7] and Houghton et al. [8]. In the experimental researches, the interesting two peaks of SMI when the groove's axial location is changed are revealed, as shown in literature [8], while the groove locates between the two peaks generates almost no SMI. This phenomenon is difficult to be explained with the common view that the groove near the leading edge generates higher SMI as the spillage of TLF is postponed more effectively [1,3]. Furthermore, it also implies the effects of single groove on the passage flow may be different as its axial location is changed, especially for the groove locating between the two peaks of SMI. In order to better reveal the grooves' mechanism, the phenomenon of the two SMI peaks should be further studied, which is the initial motivation of this paper. 
As for the SMI of groove treatment, it has been mentioned that it is attributed to the delay of TLF spillage. In most modern compressors, this spillage is observed in blade tip region which leads to the spike-type stall inception (Vo et al. [6], Ann Review [9]). As a common view, the spike-type stall inception is the short-scaled disturbance with relatively high propagation speed when compared with the modal type, which was summarized by Day [10]. On the other hand, Wyer et al. [11] found that the groove treatment has no effect on the stability for the highly hub-loaded compressor. These literatures indicate the effects of groove treatment most probably focus on tip region flow. Furthermore, if the two SMI peaks found in single groove tests are considered, whether the grooves at various axial locations correspond to different effects on tipregion flow becomes an interesting issue worthy of study. In fact, Du et al. [12] already discussed the stall inception with the single groove treatment by numerical simulations, in which it was concluded the stall inception is relatively long-scaled for the groove locating between the two peaks of SMI but generating no SMI. In this regard, the change of stall inception caused by single groove is a meaningful topic, which will be further discussed in this paper.

Based on this background, the main goal of this paper is to discuss the impacts of single groove treatment on stall inception. As a fundamental research, the change of flow features in blade tip region by single groove will be detailed studied rather than designing a casing treatment with higher SMI. According to the interesting SMI trend of single groove found in previous researches, two typical axial locations are selected for the tests in a low-speed axial compressor: one groove locates between the two peaks of SMI but is ineffective in SMI, while the other groove generates quite high SMI which locates near the second peak of SMI. The fast-response pressure transducers are mounted on casing in both the chordwise and circumferential direction in order to capture the appearance and development of stall inception. The appearance of stall inception is demonstrated with the contour of the static pressure on casing, and its development is further studied by wavelet analysis. Based on these experimental results, the scale and development of stall inception with and without single groove treatment are compared. Besides, as the further study for the single groove with almost no SMI, the design of double grooves treatment containing this groove is also tested to confirm its effects on stall inception. In the last section, the possible tip-region flow structure which leads to the change of stall inception is discussed based on both the experimental results in this paper and previous CFD simulation.

\section{Experimental Set-Up}

A low-speed axial compressor is used for the experiments in this paper, which is an in-house compressor for fundamental research associated with compressor stall. The blades are designed based on one stage of a high-pressure compressor. As the research in this paper is focused on the change of stall inception caused by single groove and the corresponding flow features in blade tipregion, the IGV and stators are not included, which means a single rotor structure in the experiments. The structure of the test-rig is shown in Fig 1 (a), and Fig 1 (b) is the detailed illustration for groove treatment. The parameters of the tested compressor are listed in Table 1.

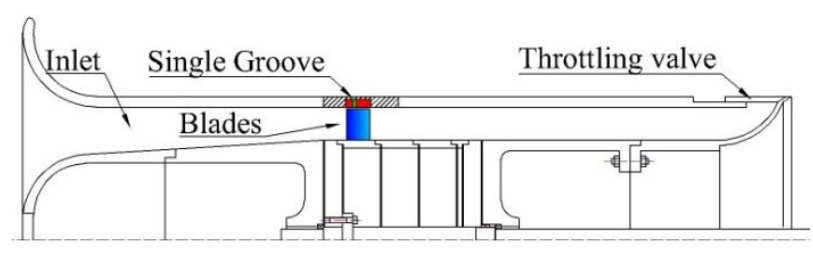

(a) The Structure of the Test-Rig

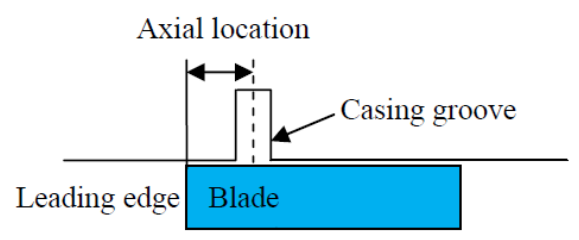

(b) The Groove Treatment

Fig 1 Illustration for the Test-Rig and Groove Treatment

Table 1 Parameters of the Tested Compressor

\begin{tabular}{cc}
\hline \hline Design Flow Rate $(\mathrm{kg} / \mathrm{s})$ & 3.2 \\
Design Rotating Speed (rpm) & 2400 \\
Number of Blades & 60 \\
Casing Diameter (mm) & 500 \\
Blade Tip Chord $(\mathrm{mm})$ & 36.3 \\
Tip Clearance $(\mathrm{mm})$ & 0.70 \\
Aspect Ratio & 1.74 \\
Hub to Tip Ratio & 0.75 \\
Tip Stagger Angle $\left(^{\circ}\right)$ & 39 \\
\hline \hline
\end{tabular}

In the experiments, the compressor is gradually throttled by step motor until the occurrence of stall. During this process, the steady measurements are continuously performed for the calculation of characteristic curve.

In this test-rig, Li et al. [13] have already studied the single groove with the width of $3 \mathrm{~mm}$ and depth of $6 \mathrm{~mm}$. In their research the axial location of the groove was varied from $0.4 \%$ to $98.3 \% C_{\mathrm{a}}\left(C_{\mathrm{a}}\right.$ is the axial chord length), and two peaks of SMI were found in these tests, as shown in Fig 2. Based on this research, the single groove with the same geometry will still be tested in this paper. The groove's 
naming is also the same with literature [13]. According to the SMI trend, two typical locations are selected for the study in this paper. One groove is CG5 with the axial location at $27.1 \% C_{\mathrm{a}}$, which is between the two peaks of SMI but ineffective in SMI. The other groove is CG7 locating at $42.7 \% C_{\mathrm{a}}$. CG7 is selected for two reasons: 1) it locates near the second SMI peak, which is higher than the first peak near the leading edge; 2) it is also not far from CG5 which can be deemed as a comparison with CG5. As the two grooves show quite different effects on stall margin, they will be tested together with the smooth casing (SC, without treatment) in this paper in order to compare the impacts of the two grooves on stall inception.

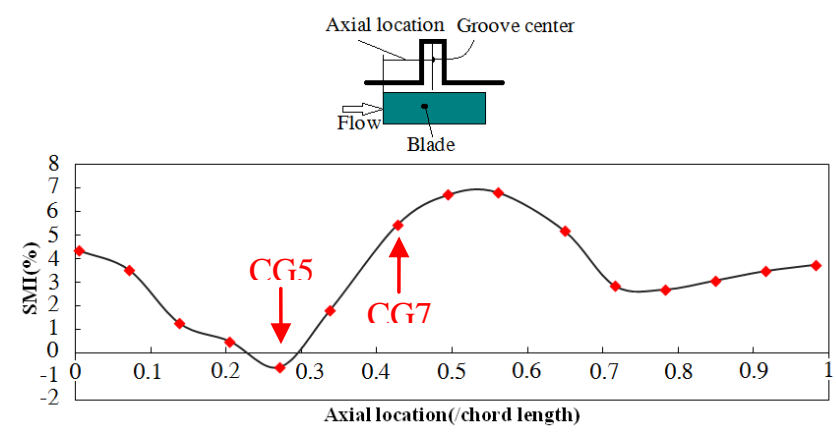

Fig 2 SMI Trend with Single Groove's Axial Location [13]

In the experiments the steady measurements for the calculation of characteristic curve are considered first. The characteristic curve is expressed with the flow coefficient $\varphi$ and pressure rise coefficient $\psi$, which are defined by Equation (1) and (2):

$$
\begin{aligned}
& \varphi=\frac{V_{1}}{U} \\
& \psi=\frac{P_{2, s}-P_{1, t}}{\frac{1}{2} \rho U^{2}}
\end{aligned}
$$

At the inlet of the rotor, four $0.5 \mathrm{~mm}$ pneumatic holes with equal circumferential spacing are used to measure the inlet static pressure on casing. The inlet total pressure $P_{1, \mathrm{t}}$ is also measured by total pressure probe. The incoming flow velocity $V_{1}$ in Equation (1) is then obtained by ambient density $\rho$ and the difference between the inlet total and static pressure, while $U$ is the tangential speed of the blade at midspan (about $55 \mathrm{~m} / \mathrm{s}$ at design rotating speed). In Equation (2), the static pressure $P_{2, \mathrm{~s}}$ is also measured by four holes locating about ten times of $C_{\mathrm{a}}$ away from the rotor outlet. All of these parameters are continuously measured with the sampling frequency of $1 \mathrm{~Hz}$ during the throttling process, and then the characteristic curve is obtained by the two equations. Each casing is tested for several times to verify whether the flow coefficient when stall occurs (the last stable point on the characteristic curve) agrees well in the tests. The error is less than $0.5 \%$ for the same casing, which is sufficiently accurate to distinguish the SMI of the tested grooves.

Besides the steady measurements, most of the attention in this paper will be paid on the dynamic measurements. The fast-response pressure transducers (Kulite XCS-190) are used in the experiments. They are mounted on casing in two ways: ten transducers concentrated mounted as a line (group A) and eight transducers mounted in the circumferential direction (group B), as shown in Fig 3 (a) and (b) respectively. The mounting of group A in Fig 3 (a) is the illustration for smooth casing, in which the angle between the mounting line of sensors and the circumferential direction is $14^{\circ}$. The distance between neighboring sensors is $11 \mathrm{~mm}$. For the casing with the single groove treatment, the mounting angle and distance are slightly different due to the presence of the groove. In Fig 3 (b), all of the eight transducers are mounted aligned with the leading edge of blade with equal circumferential spacing $\left(45^{\circ}\right.$ between each other) for capturing the appearance of stall inception.

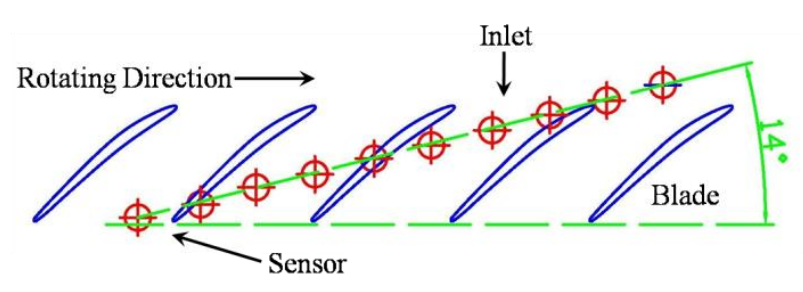

(a) Concentrated mounted as a line (Group A)

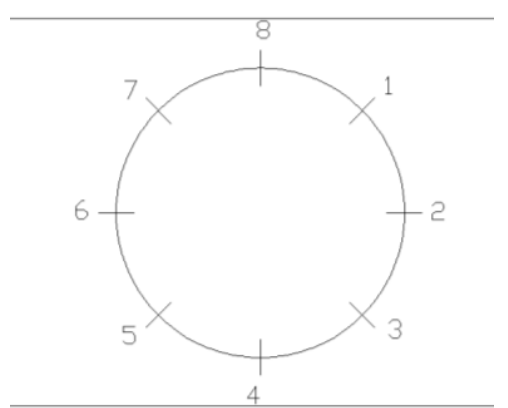

(b) Mounted in the circumferential direction (Group B) Fig 3 The Mounting of Pressure Transducers

A FYLDE amplifier is used for the signal conditioning of the transducers in the experiments, and the data is acquired at the sampling frequency of $100 \mathrm{kHz}$ by DAQ devices. In order to capture the developing process of stall inception, the data acquisition lasts for several hundreds of rotor revolutions in the final throttling process until the formation of the full developed stall cell.

\section{Effects of the Single Grooves on Stall Margin}

According to the steady measurements, the characteristic curves with and without single groove treatment are obtained. Before the discussions about the change of stall inception, the effects of the single 
grooves on stall margin are demonstrated first in this section.

The characteristic curves for smooth casing and the single grooves CG5 and CG7 are displayed in Fig 4. The curves demonstrate the whole flow range for each casing and the process to quit the stall (the bottom of the curves). It can be seen that the operating range is obviously extended by CG7 while the curve still conforms well to that for SC. As for the groove CG5, it has almost no impact on stall margin. In order to assess the groove's ability to extend the operating range, the parameter of SMI is then defined. As the pressure ratio is only a little higher than one and varies little in the operating range for the low-speed compressor in this paper, the pressure ratio is not considered in the calculation of SMI, which is then defined as:

$$
\mathrm{SMI}=\left(\frac{\varphi_{\mathrm{SC}, \text { stall }}}{\varphi_{\text {Groove,stal }}}-1\right) \times 100 \%
$$

The subscript "stall" in Equation (3) indicates the flow coefficient corresponds to the point of stall inception. The SMI is then found to be $-0.1 \%$ for CG5 while it is $5.7 \%$ for CG7, which means CG7 effectively improves the stall margin but CG5 shows almost no impact on stall margin.

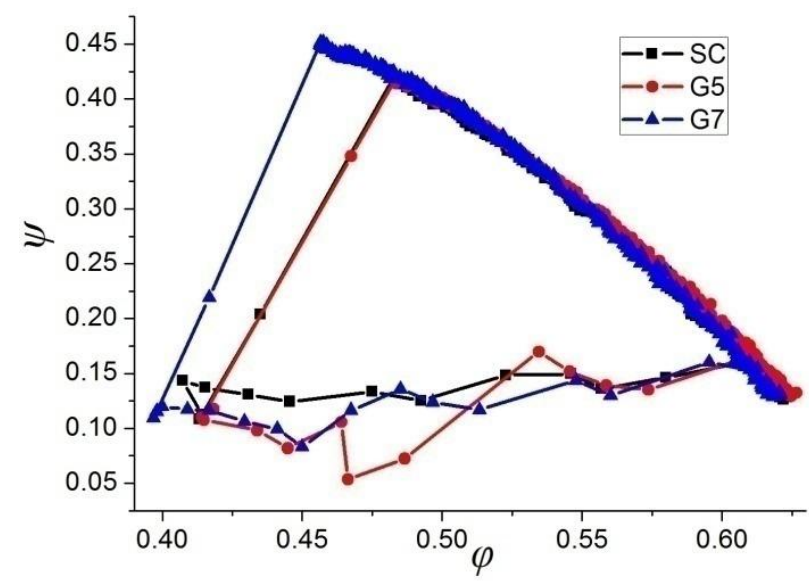

Fig 4 Characteristic Curves of SC, CG5 and CG7

Based on the results of steady measurements, the effects of single grooves on stall margin are discussed in this section. In the following sections, the unsteady measurements by fast-response pressure transducers will be further performed. The intent is to experimentally study the features of stall inception with and without single groove treatment, which is the main goal of this paper. The data measured by transducers of group A and B will be analyzed respectively.

\section{Contour of static pressure on casing when stall inception appears}

In the final throttling process, the data is continually acquired for the fast-response transducers until the formation of the fully developed stall cell. As for the compressor tested in this paper, it is believed the stall inception is the typical spike-type in previous researches, such as literature [12] and [13]. It has been mentioned in the introduction that the spike-type stall inception is the short-scaled disturbance with relatively high propagation speed. In this regard, these features of stall inception will be mainly studied with the experimental results in the following sections.

The data is continuously acquired for the transducers of group $\mathrm{A}$ in the final throttling process until the formation of the fully developed stall cell. The contour of static pressure on casing for each rotor revolution (60 passages) is then obtained. These contours are checked one by one, and the first observed breakdown of flow structure in blade passages in these contours is deemed as the stall inception found in this test. As for the smooth casing, the first observed stall inception is displayed as the contour of static pressure on casing in Fig 5 (a).

In this figure, 60 blade passages of the whole annulus are demonstrated and the abscissa is the time series in unit of blade passages. The stall inception is found in the passage series of 3990 to 3996 shown by the red box, which means its circumferential scale is about 5 7 passages. When it is observed the next time in about 1.5 revolutions (90 passages) later, its circumferential scale already extends to about 30 passages (half of the annulus), as shown in Fig 5 (b). In the subsequent contours this observed flow structure continuously propagates with the circumferential scale of about 30 passages and the propagating speed of about $50 \%$ rotating speed. These features indicate it already turns into the fully developed stall cell. The results found for $\mathrm{SC}$ also conform to the features of the typical spiketype stall inception. 


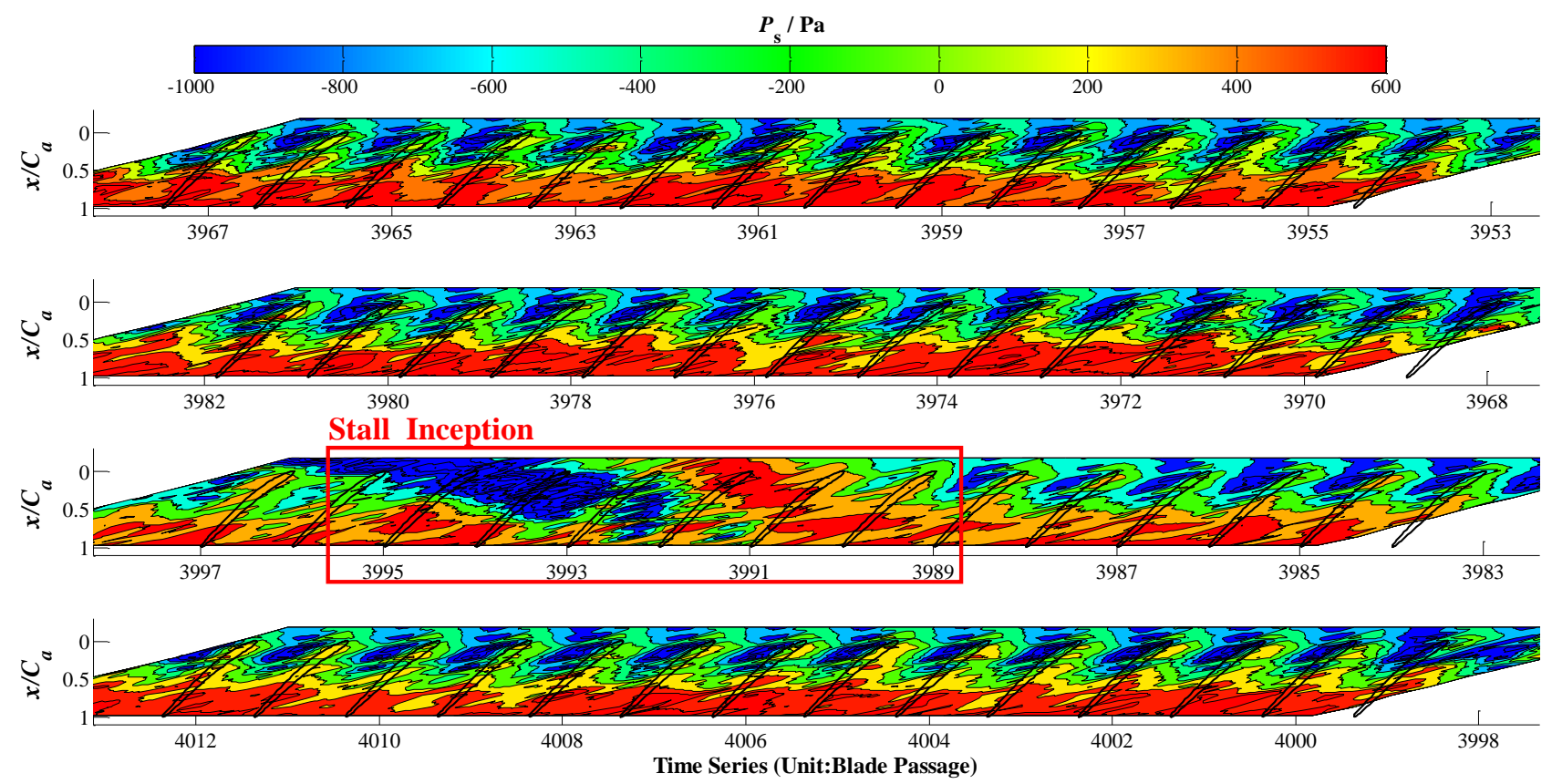

(a) The first observed stall inception
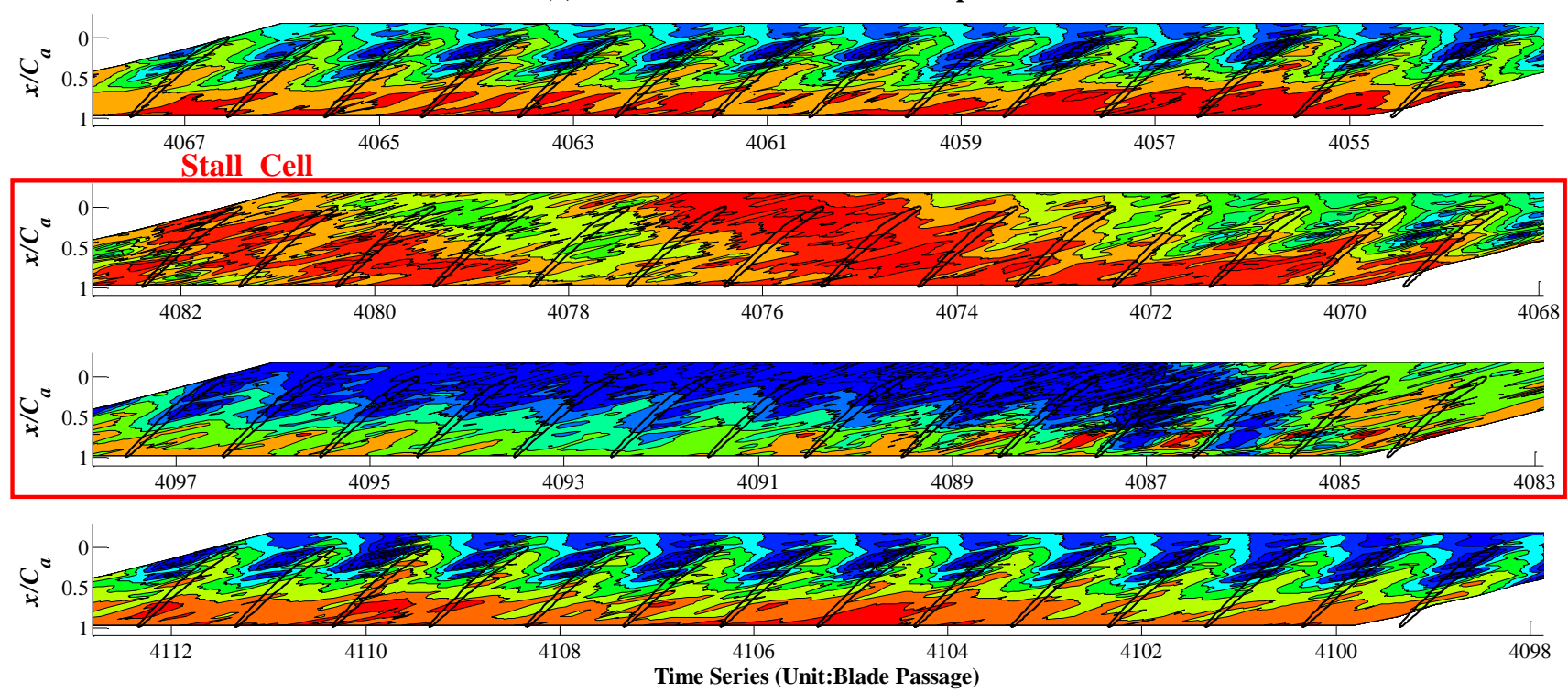

(b) Fully developed stall cell

Fig 5 Contour of Static Pressure on Casing when Stall Occurs, Smooth Casing (SC)

Based on these analyses for SC, the stall inception found for CG5 and CG7 will be studied, which are shown in Fig 6 (a) and (b) respectively.

In Fig 6 (a), the stall inception is observed in the passage series of 4629 to 4641 (more than 10 passages), and it also turns into the fully developed stall cell in the next 1 2 revolution. The appearance of stall inception and its developing process for CG5 are still similar to those for SC, while the circumferential scale of the stall inception is more than 10 passages when it is first observed.

Fig 6 (b) is the contour for CG7. The stall inception is first observed in the passage series of 4096 4102, which turns into the fully developed stall cell in the next 1 2 revolution. As for CG7, there is no obvious difference between the features observed for this groove and for SC. 

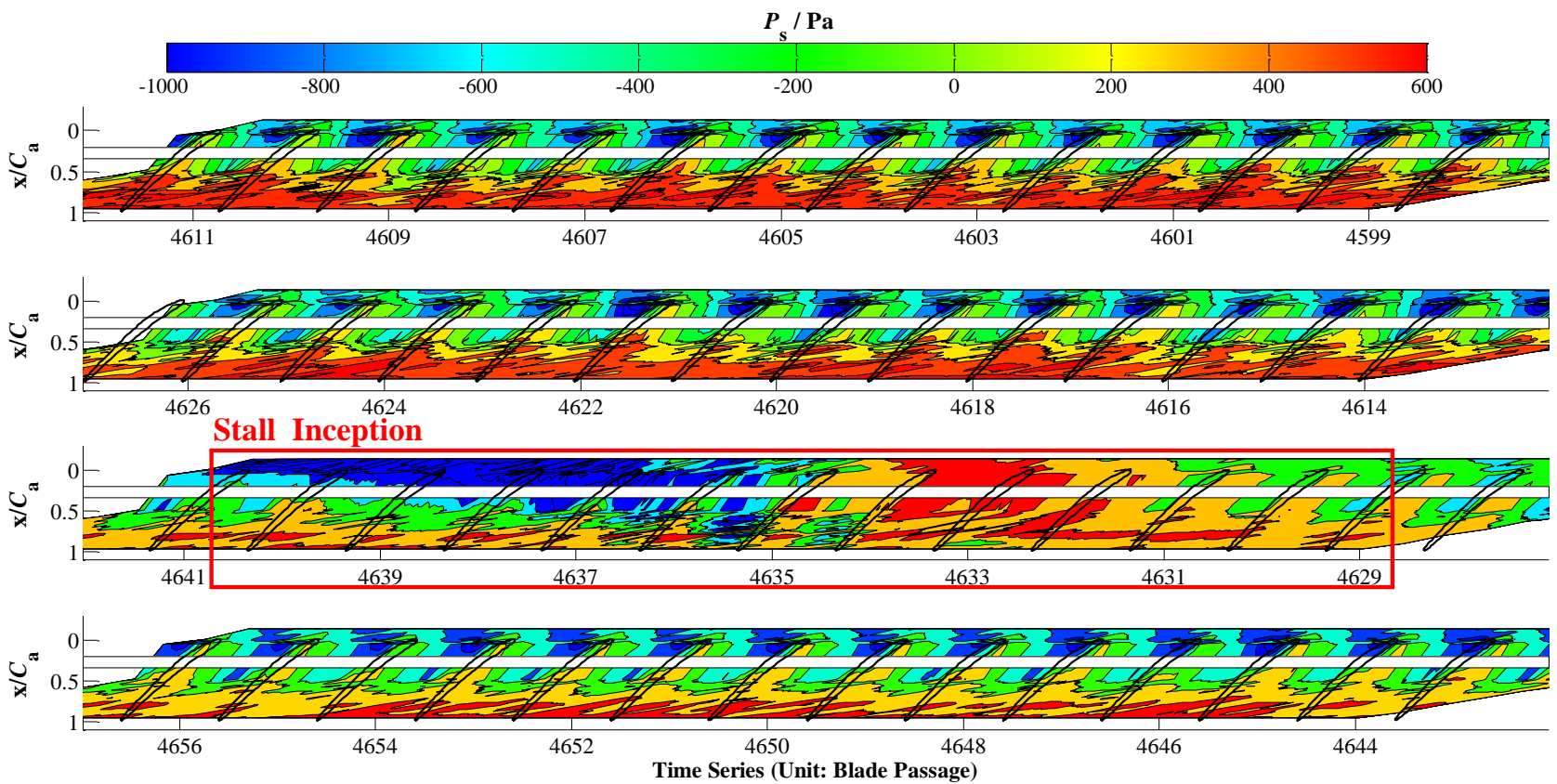

(a) CG5
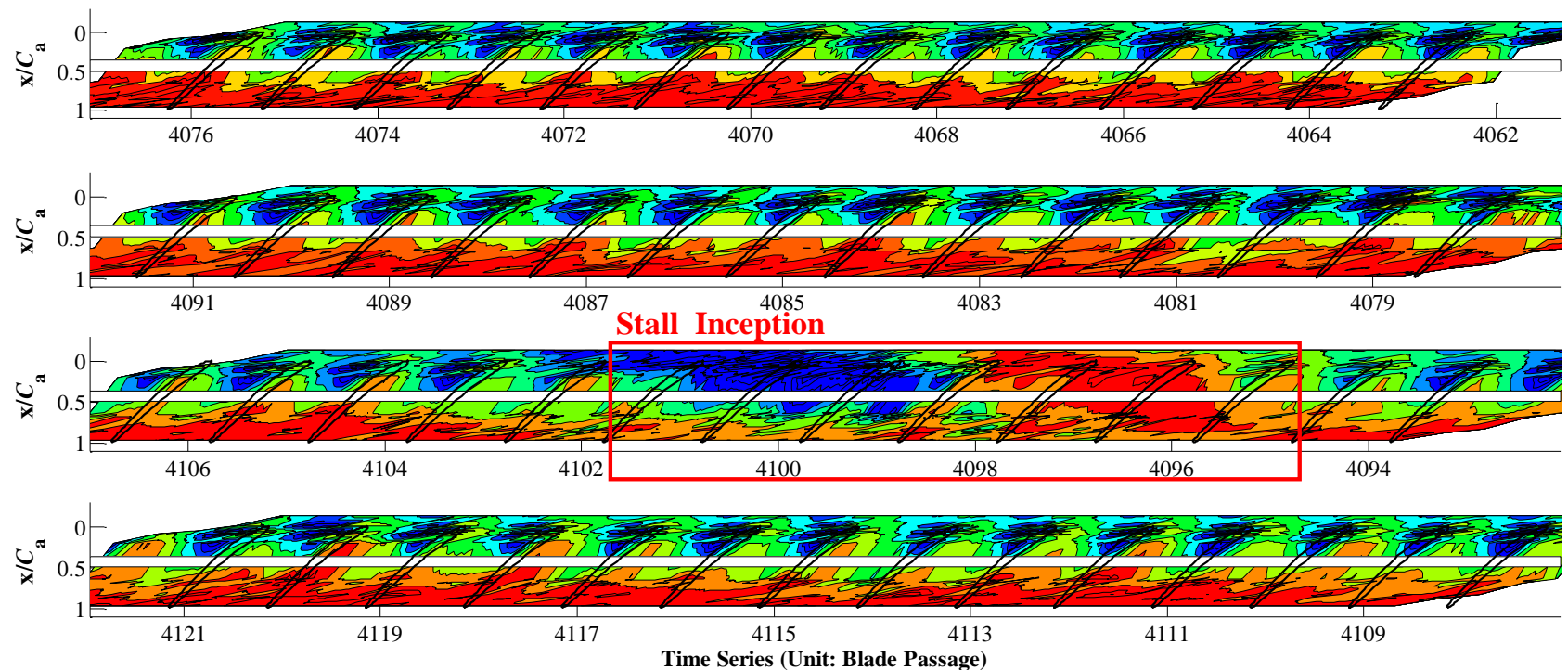

(b) CG7

Fig 6 Contours of Static Pressure on Casing when Stall Inception is First Observed, with CG treatment

According to Fig 5 and Fig 6, it can be found that for both SC and CG7, the stall inception occupies about 5 7 blade passages when it is first observed and turns into the fully developed stall cell just 1 2 revolution later. These features conform to the typical spike-type stall inception. As for CG5, the stall inception also turns into the stall cell rapidly, which is the same with SC, while its circumferential scale is more than 10 passages when it is first observed in Fig 6 (a). In this regard, the contours of static pressure on casing indicate the longer circumferential scale of stall inception exist for CG5. However, it should be noted the contours are obtained by transducers mounted within the circumferential coverage of only 3 4 blade passages (shown in Fig 3 (a)) while there are 60 passages for the tested rotor. Thus the coverage of transducers is not wide enough to promptly detect the stall inception when it appears, which means the stall inception has probably propagated for a certain number of passages when it is observed in these figures. The further study is then desired to confirm the findings in these contours, and more accurate detection of stall inception will be discussed in the following section. 


\section{Wavelet Analysis of Stall Inception with the Data Measured in the Circumferential Direction}

In this section, the data measured by transducers mounted in the circumferential direction will be processed in order to accurately detect the appearance of stall inception. In these tests, the stall inception is usually reflected as the abrupt change in the signal acquired by the transducers. To this end, the method of wavelet analysis will be used as it is an appropriate time-frequency analysis tool for signal singularity detection. In this regard, Lin et al. $[14,15]$ proposed a continuous 1-dim wavelet analysis tool to detect the stall inception (appeared as small disturbance) in compressors through wavelet analysis, in which the wavelet transform is defined as:

$$
W_{x}(a, b)=\frac{1}{\sqrt{a}} \int_{-\infty}^{\infty} x(t) \Phi\left(\frac{t-b}{a}\right) d t
$$

The tool will also be exploited for the detection of stall inception in this paper. In Eq. (4), $x(t)$ is the input signal to be processed (the pressure data), while $a$ and $b$ are the scale and shift of the base wavelet $\Phi$ which will be compared with the input $x(t)$ in wavelet transform. According to literature [14] and [15], the "Morlet" wavelet is also used as the base wavelet in this paper. As for a specified scale, the center frequency could be determined for the base wavelet in Eq. (4), so the scale domain is then linked to the frequency domain. The parameter $b$ corresponds to the time shift for the pressure data. $W_{x}(a, b)$ is the output of wavelet transform representing the similarity between the input and base wavelet. In this paper, both the scale $a$ and time shift $b$ are varied in the wavelet transform thus the time-frequency analysis is performed.

As the stall inception is usually reflected as the abrupt change in the acquired signal, its features can be recognized through wavelet transform in both the time and frequency domains. As an example of detecting the stall inception by wavelet analysis, the processing results for the data of transducer Chan 1 in group B are shown in Fig 7. The tested casing is the smooth casing (SC) in this figure. Subfigure (b) is the results of wavelet power spectrum for the original time-domain signal in subfigure (a), and its color bar corresponds to the power level of wavelet spectrum. In addition, the scale range in the transform of Eq. (4) is converted to the frequency range shown in subfigure (b) and normalized by blade passing frequency (BPF). Due to the limitation of signal length, the black bowl-shape curve is also plotted in subfigure (b) to show the "Edge Effect", below which this effect is significant, and only the part above this curve will be discussed. Subfigure (c) is the global wavelet spectrum (GWS) which integrates the wavelet power spectrum along the time axis in subfigure (b), and it is deemed as the power spectrum distribution in frequency domain by wavelet transform. As a comparison, subfigure (d) is the traditional FFT power spectrum.

In Fig 7, the first observed stall inception is shown in the time-domain signal (subfigure (a)). According to the magnitude of wavelet power spectrum, the stall inception can also be found as the blue "spot" with high power level in subfigure (b), and in the subsequent revolutions the stall cells are observed. This blue "spot" also indicates the first observed stall inception corresponds to the characteristic frequency of about $0.0625 \sim 0.125 \mathrm{BPF}$. As the "spot" is a local phenomenon and the data is continuously acquired for the rotating blades, in fact this characteristic frequency found in the data represents the circumferential scale of the observed stall inception or cell. For example, if the stall inception is on the scale of $n$ passages, its length in time-domain signal should be $n$ times of the blade passing period, which means its characteristic frequency is $1 / n$ BPF in frequency domain. Though the growth of stall inception or cell when it passes through the transducer also causes its length to be longer in the acquired data, this effect is believed to be not obvious for stall inception as it covers only a few passages, and only for stall cell it is necessary to be considered. As the further illustration for this issue, subfigure (b) is zoomed in to show the first observed stall inception in Fig 7. The frequency of $0.0625 \sim 0.125 \mathrm{BPF}$ in power spectrum corresponds to the scale of 8 to 16 passages for the stall inception, while the center of the blue "spot" is roughly about $0.1 \mathrm{BPF}$ (10 passages). In fact the time-domain signal indicates it covers about 10 passages, which means the circumferential scale is correctly detected by the wavelet transform.

In contrast with the traditional FFT analysis and the direct time-domain observation, the stall inception as well as its circumferential scale can be more easily determined by the 2-dim wavelet spectrum, which is believed as the advantage of this method. Based on the example shown in Fig 7, the data acquired by the eight transducers of group $B$ for both the smooth casing and the two single grooves will be analyzed. 


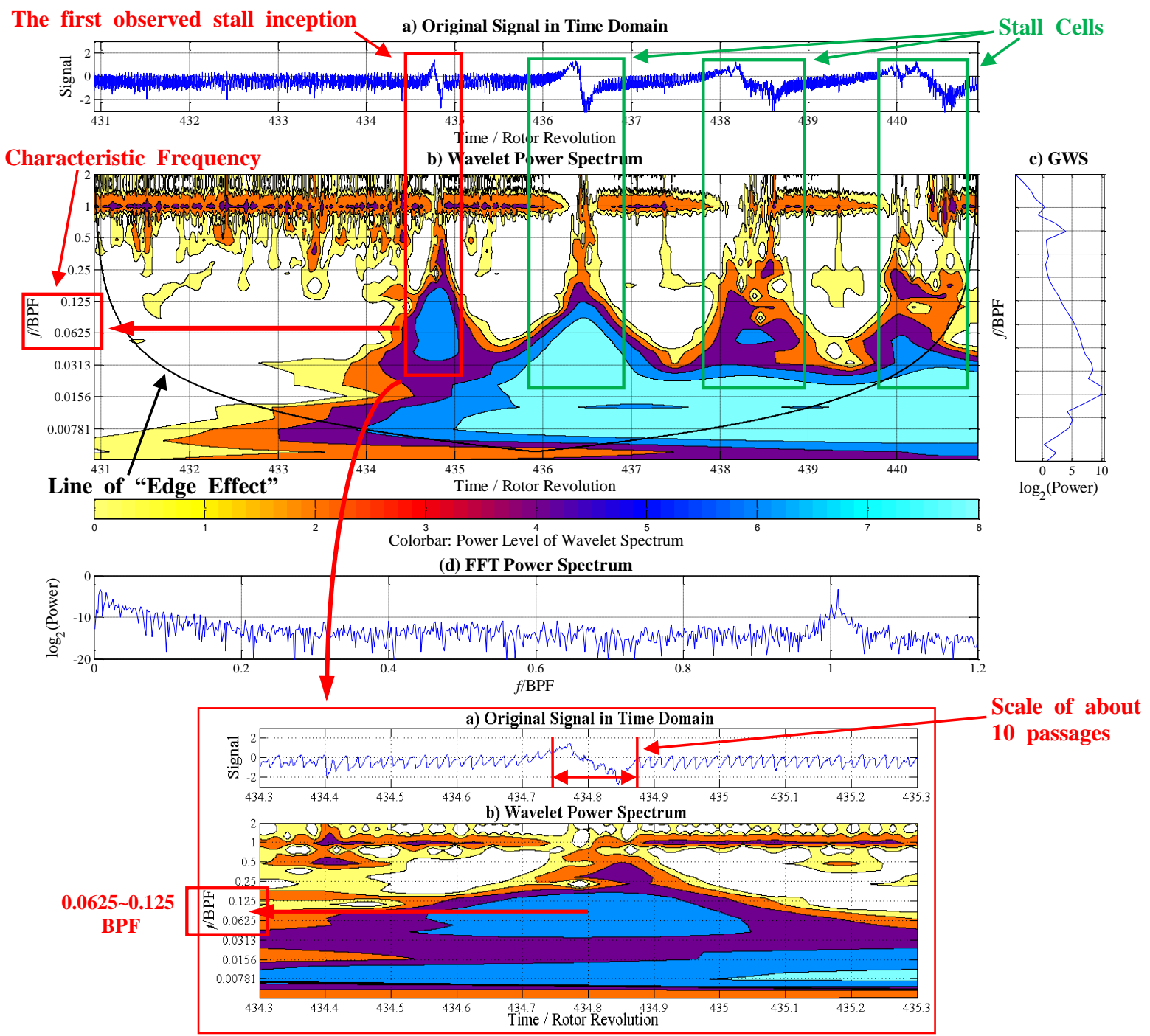

Fig 7 An Example of Detecting the Stall Inception by Wavelet Analysis, Chan 1 in Group B (SC)

The wavelet analysis for each transducer is performed for the smooth casing first. These results are successively displayed in Fig 8 according to the transducers' circumferential locations. The fully developed stall cell is observed after revolution 434, which is propagating at the speed of about 50\% rotor speed, indicated by the black arrow. Before the formation of stall cell, a disturbance can be found to be propagating across these transducers, shown by the red arrow. It is continuously growing up and finally turns into the stall cell after about 2 4 rotor revolutions. This disturbance is first observed in Chan_1 at about revolution 432 (the red circle), which is deemed as the appearance of stall inception found in this figure.

According to the slope of the red arrow, the propagation speed of the stall inception is calculated, which is about $70 \%$ of rotor rotating speed. Besides, when the stall inception is first detected by Chan_1, its characteristic frequency is about $0.25 \sim 0.5 \mathrm{BPF}$ (the green arrow), and this range corresponds to $2 \sim 4$ blade passages. These features are somewhat different from what are observed in the contours of Fig 5 because the more accurate and timely detection for the appearance of stall inception can be achieved by eight circumferentially mounted transducers along the whole annulus for group B. When the stall inception appears, it can be detected by one of these transducers in time. Thus the stall inception covers less blades passages in Fig 8 than what is observed in Fig 5, and this also causes more revolutions for the stall inception to develop into the fully developed stall cell. In consideration of the features found in Fig 8 (the circumferential scale and propagation speed of stall inception), it is believed to be the typical spike-type stall inception for smooth casing (SC). 


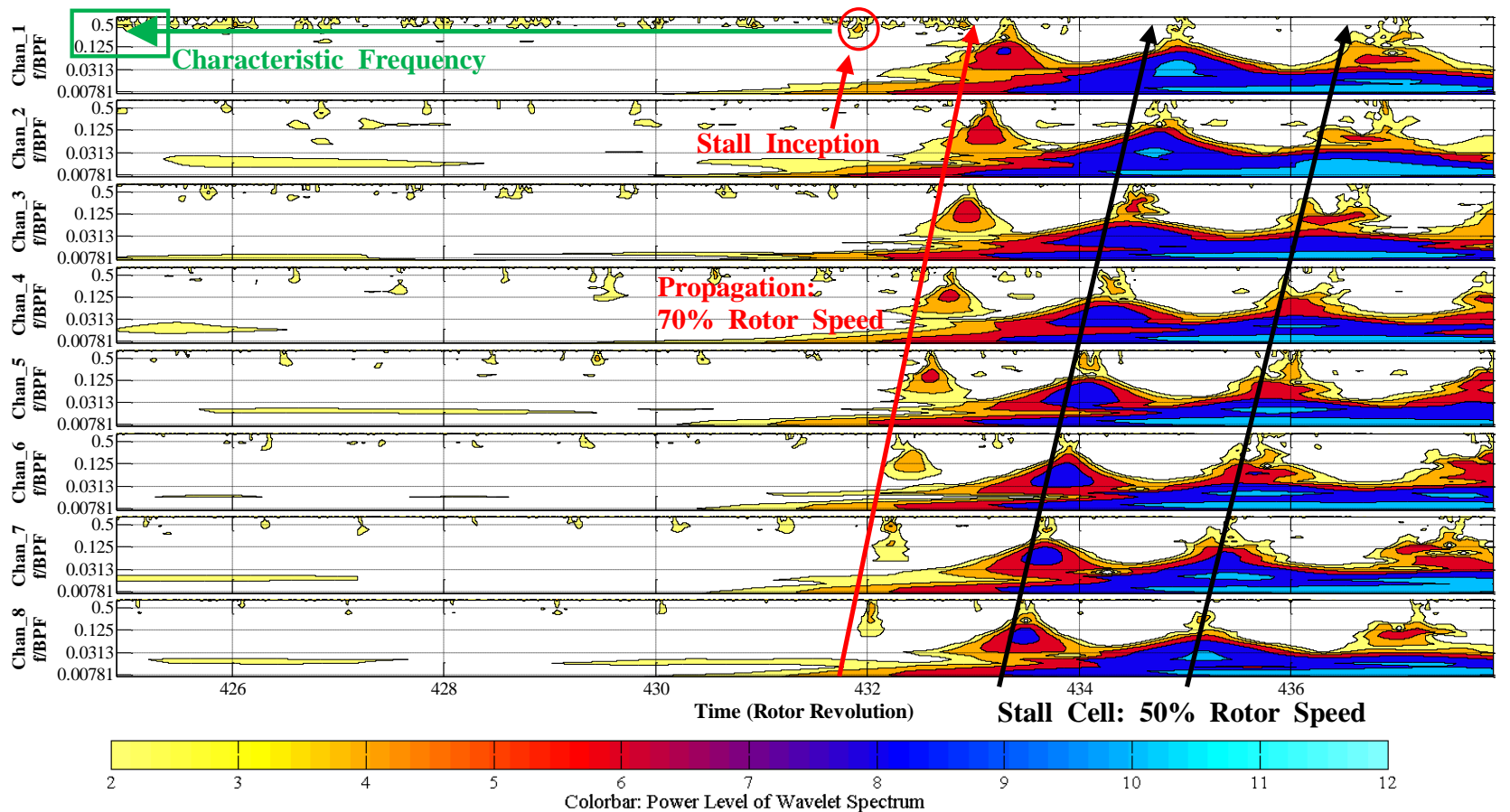

Fig 8 Circumferential Detection of the Stall Inception by Wavelet Analysis, Smooth Casing (SC)

On the basis of the analysis for SC, the results for CG5 and CG7 are then studied, which are displayed in Fig 9 (a) and (b) respectively. As for CG5, the propagation speed of stall inception is found to be similar to the speed observed in Fig 8, which is also about $70 \%$ of rotor rotating speed. However, the corresponding frequency of stall inception when it is first observed is below 0.125 BPF, shown by the green arrow. This means the stall inception occupies more than 8 passages when it appears in this figure and is relatively longer-scaled when compared with smooth casing. With regard to CG7, the frequency of stall inception is $0.25 \sim 0.5 \mathrm{BPF}$ in Fig 9 (b) which corresponds to $2 \sim 4$ passages, and the slope of the red arrow indicates the propagation speed is also about $70 \%$ of rotor rotating speed. These features are similar to those observed for SC in Fig 8.

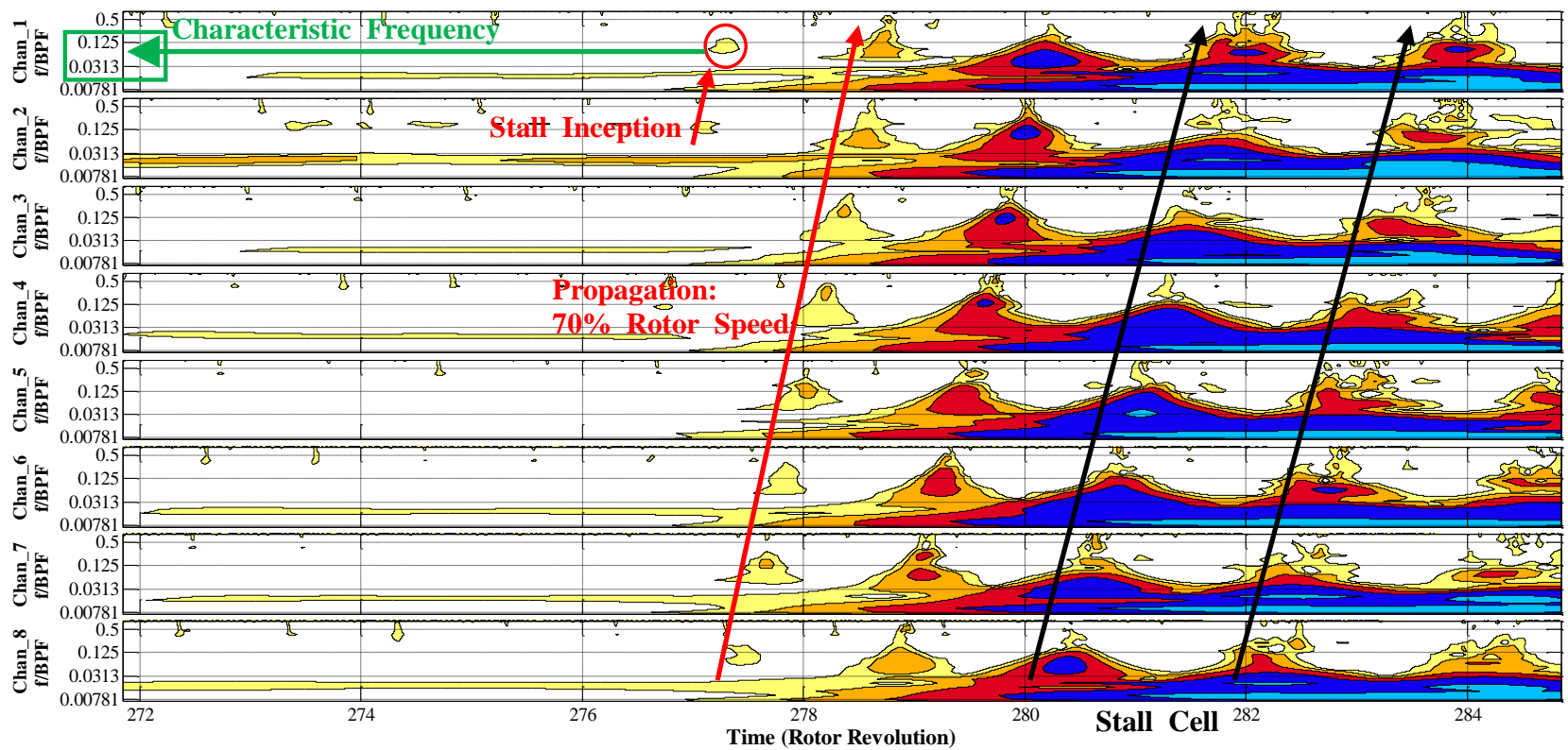

(a) CG5 


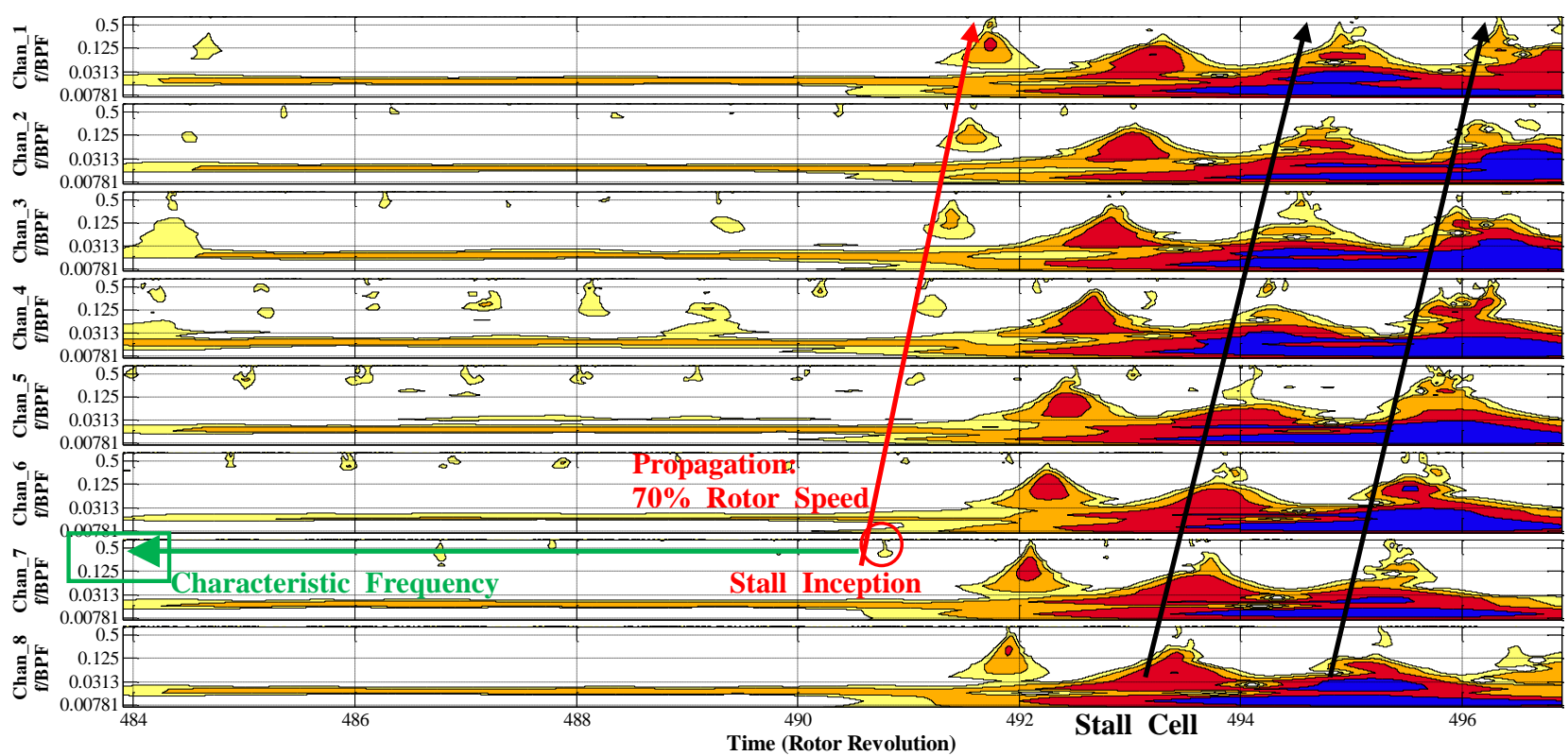

(b) CG7

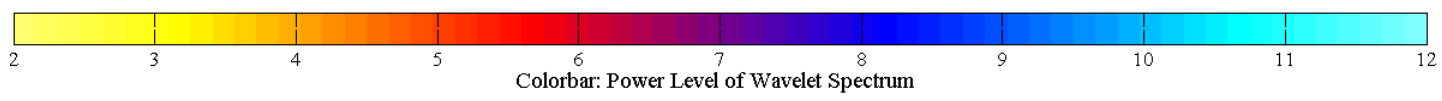

Fig 9 Circumferential Detection of the Stall Inception by Wavelet Analysis, with CG treatment

Based on the above wavelet analysis of the data acquired by transducers of group $B$, the circumferential scale and developing process of the stall inception are further revealed for smooth casing and single grooves. Fig 8 indicates it is typical spike-type stall inception for SC, and the features for CG7 are also found to be similar to those for SC. However, the stall inception for CG5 occupies more than 8 passages when it is first observed, which means its circumferential scale is longer than SC and CG7 (2 4 passages). The scales in these results are different from those in static pressure contours as the stall inception can be detected promptly by these circumferentially mounted transducers when it just appears, thus it is found to occupy less blade passages in wavelet analysis as it does not take too much development. Through the comparison between SC, CG5 and CG7, the wavelet analysis confirms the finding in the contours of static pressure on casing: the stall inception is typically short-scaled for SC and CG7 while it is relatively longer-scaled for CG5.

According to the analysis in the above sections, the impacts of the single grooves CG5 and CG7 on stall inception have been studied, and the relatively longer-scaled stall inception is found for CG5. In this regard, CG5 becomes a quite interesting groove which modifies the circumferential scale of stall inception while provides almost no SMI. On one side, the effects of CG5 on blade tip-region flow should be further researched to clarify the possible relation between the modification of stall inception scale and the low SMI. On the other side, though the impacts of CG5 are found to be different in the single groove tests, some further verification is still desired to confirm the above results. This will be considered in the next section.

\section{Further Tests on Double Grooves Treatment}

As the main interest of this paper, it is revealed by previous analysis on single groove that the relatively longer-scaled stall inception exists for the single groove CG5. In this regard, more study will be considered in this section about CG5's effects. A further issue is that whether CG5 only takes effect in single groove treatment or it still modifies the stall inception even in case of multiple grooves. If the stall inception is always affected by CG5, this groove's effects on stall inception can be further confirmed, and it also indicates the tip-region flow is changed by CG5 in a special way which deserves more clarification.

As a simple attempt on basis of single groove treatment, the design of double grooves treatment containing CG5 is considered to discuss CG5's effects when combined with another groove. In this regard, the locations of these two grooves should be determined first. Though the single grooves of CG5 
and CG7 have been tested, the combination of these two grooves is difficult to be applied due to the narrow spacing between the two grooves. As the substitute for CG7, another groove CG9 is combined with CG5. Its center locates at $56.1 \% C_{\mathrm{a}}$ after blade leading edge, which is behind CG7 and also close to the second SMI peak. The parameters of CG9 are still the same with the previous tested grooves (width of $3 \mathrm{~mm}$ and depth of $6 \mathrm{~mm}$ ). This double grooves treatment is then named as CG59.

The steady measurements show that CG59 generates quite high SMI $(5.2 \%)$ in contrast with CG5, which can be deduced to mainly result from CG9. In the test, the transducers of group B are still used to detect the appearance and development of stall inception. The results of wavelet analysis for the acquired data are displayed in Fig 10. The propagation speed of stall inception is still about $70 \%$ of rotor rotating speed in this figure, and the corresponding frequency is below $0.125 \mathrm{BPF}$ when the stall inception appears. These features in CG59 test indicate the stall inception is relatively longerscaled with more than 8 passages, which are also the same with the test for single groove CG5. In this regard, the stall inception is also modified with the treatment of double grooves CG59.

According to the study on the single and double grooves treatment, it is indicated the stall inception is relatively longer-scaled with CG5 treatment in both of the two cases. On the other side, the typical spike-type stall inception with relatively short circumferential scale is found for smooth casing, and the groove CG7 shows no obvious impacts on stall inception. In comparison with SC and CG7, the groove CG5 is believed to take different effects on stall inception, which modifies its circumferential scale.

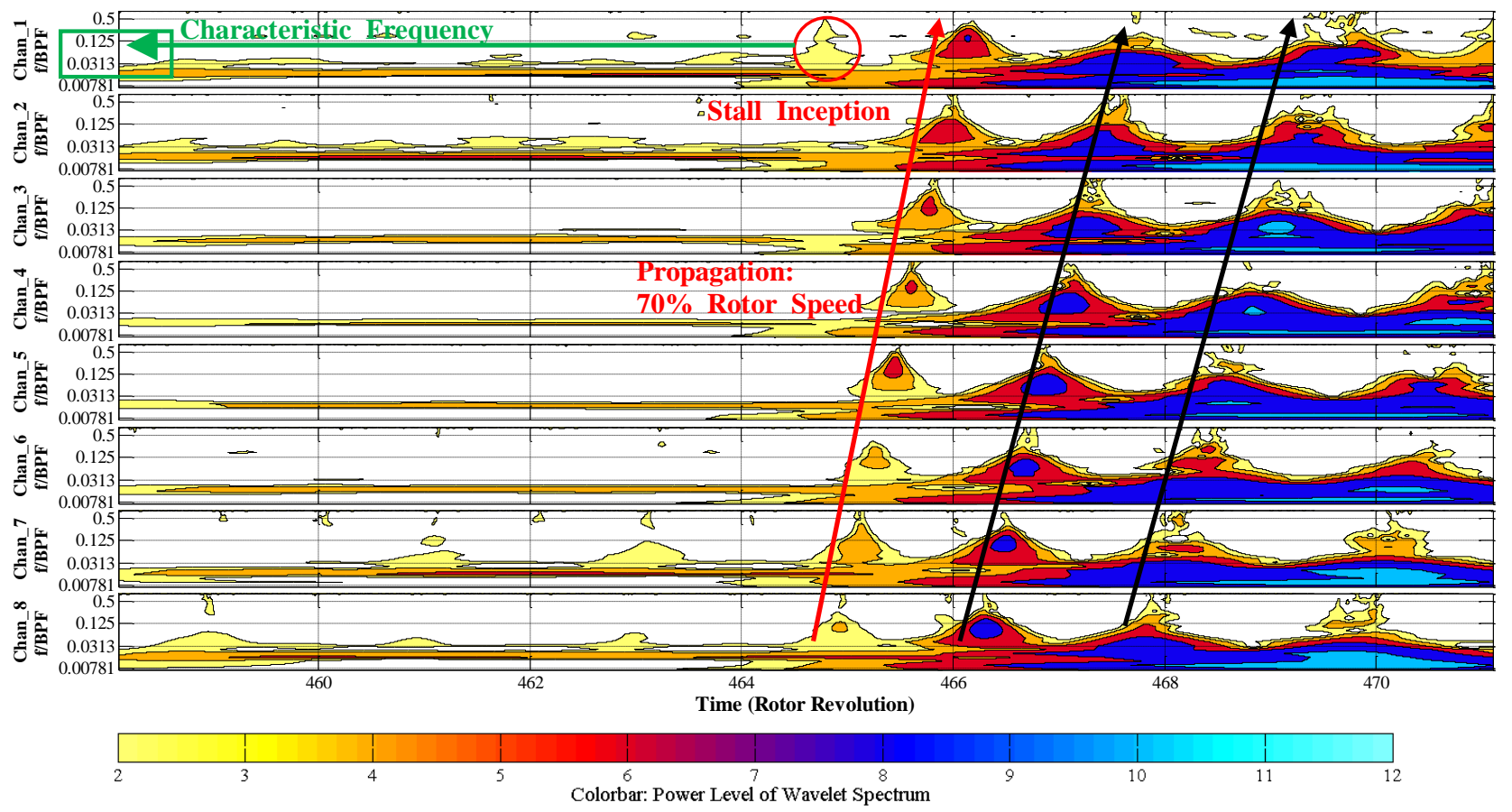

Fig 10 Circumferential Detection of Stall Inception by Wavelet Analysis with CG59 treatment

\section{Discussions: the Change of Stall Inception due to the Groove Treatment}

It has been revealed by the above analyses that the stall inception is changed into relatively longerscaled type with CG5 treatment, while it is not affected by CG7. The modification of stall inception also implies the blade tip-region flow may be affected by CG5 in a special way and it should be further studied. In this regard, the research of tipregion flow structure in blade passages with and without groove treatment should be involved. Though it cannot be achieved through the dynamic measurements used in previous sections, some further discussions on the change of stall inception and corresponding tip-region flow structure are still considered in this section based on the results in this paper and the related CFD researches.

It has been mentioned that the single grooves with the same width and depth are studied in this test-rig by CFD simulation in literature [12]. A ten- 
passage URANS model with a total grid nodes of 3.1 million is selected in this research, which is considered to be adequate to capture the flow structure related to spike-type stall inception covering 3 5 blade passages in prestall process. The standard $\kappa-\varepsilon$ turbulence model is used. For timeaccurate resolution, 30 time steps are set per blade passing period and 20 inner iterations each time step were calculated. The calculated characteristic line for smooth casing is verified to agree well with the experiments first, and then the flow details relating with prestall dynamics are discussed for the tested grooves. The tip-region disturbance observed in the simulation, which is taken as the stall inception, is displayed in Fig 11 for SC and two grooves with quite different SMI respectively.

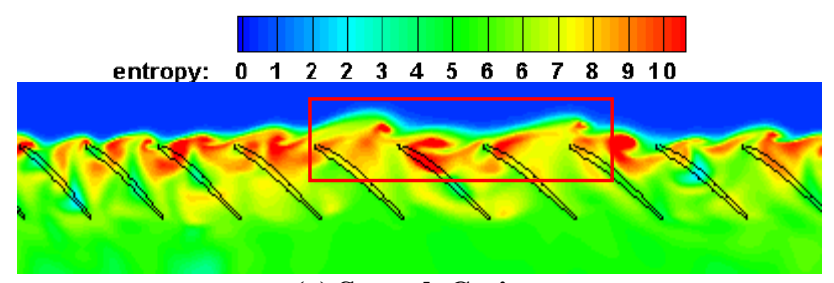

(a) Smooth Casing

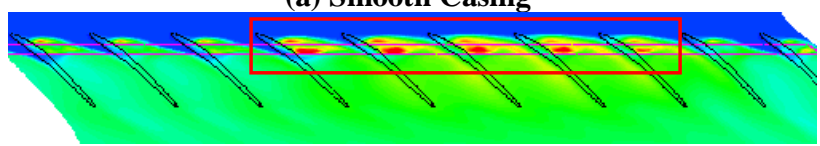

(b) The groove with almost no SMI

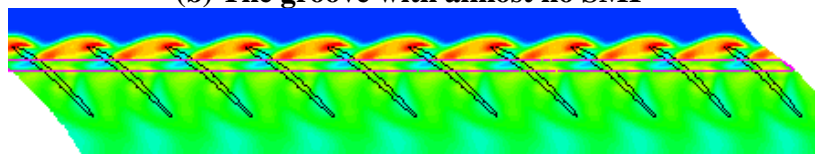

(c) The groove with effective SMI

Fig 11 Stall Inception Found in Blade Tip-Region when Flow Breaks Down by CFD Simulation [12]

It should be noted that the axial location of the grooves in Fig 11 are slightly different from the grooves in this paper, while the similar SMI trend is captured, especially for the groove near leading edge but providing almost no SMI in subfigure (b). In Fig 11 , the disturbance of only 1 2 passage originates in tip-region which evolves into spike and finally breaks the flow structure in the simulation. As for the groove in subfigure (b), the stall inception appears on the scale of about five passages, which is longer than SC. No disturbance is captured for the groove with effective SMI in subfigure (c), while the spike-type stall inception is still believed to appear due to the random disturbance in real condition. The stall inception in Fig 11 is found to cover fewer passages in CFD simulation than in the experiments as its initial status can be accurately captured in simulation. In fact, as a relative comparison, the
CFD results also indicate the longer-scaled stall inception exists for the groove with almost no SMI, which has been revealed by experimental results in this paper.

According to the above analyses, the flow mechanism for the modification of stall inception caused by CG5 becomes an interesting issue. As a further speculation based on current study about stall inception, the flow interaction between CG5 and tip-region flow at the near stall point and is believed to be the key for this modification and the formation of longer-scaled stall inception. In this regard, the change of tip-region flow caused by CG5 needs more clarification, which may be different from the common view that the tip leakage flow is weakened by groove treatment and its spillage at leading edge is then postponed.

Based on the experimental results in this paper, more work about the tip-region flow will be considered, especially for CG5. In order to directly observe the groove-passage interaction, the flow pattern at the interface between the groove and blade passage should be measured. The unsteady measurements in the planes upstream and downstream the rotor blades could also be involved to get more details about the tip-region flow. These experimental researches will be performed in future work for understanding the change of stall inception caused by CG5.

\section{Conclusions}

The impacts of the circumferential groove treatment on stall inception are experimentally studied in this paper. Two single grooves, which are ineffective (CG5) and quite effective (CG7) in improving the stall margin, are selected to discuss whether the impacts on stall inception are different for the single grooves with quite different SMI. The unsteady measurements on the casing by fastresponse pressure transducers of group A (concentrated mounted as a line) and group B (in circumferential direction) are performed for the study of stall inception.

The contours of instantaneous static pressure on casing when stall inception is first observed and the corresponding circumferential detection by wavelet analysis are discussed respectively. The typical spike-type stall inception is found for SC (without treatment) as well as the groove CG7 with quite effective SMI, which is revealed as the short-scaled disturbance in the acquired data. However, as for the groove CG5 locating between the two peaks of SMI 
but providing almost no SMI, the stall inception is found to be relatively longer-scaled than SC and CG7. The further tests of the double grooves treatment CG59 (the combination of CG5 and CG9) indicate the stall inception is still longer-scaled, which is similar to the case of single groove CG5. According to these experimental results, the groove CG5 is believed to take different effects on the compressor: it provides almost no SMI while modifies the stall inception into the relatively longer-scaled type in both the single and double grooves treatment. These results provide the validation about the change of stall inception in CFD simulation, which indicates the different effects of CG5 on the tip-region flow structure. In this regard, more experimental work about how the tip-region flow is affected by groove CG5 and its relation with the relatively longer-scaled stall inception will be considered in future work.

\section{Acknowledgements}

The authors thank for the supports by the National Science Foundation of China with project No. 51606189 and No. 51676183.

\section{References}

[1] Shabbir A, Adamczyk J J. Flow mechanism for stall margin improvement due to circumferential casing grooves on axial compressors [J]. ASME Journal of Turbomachinery, 2005, 127(4): 708-717.

[2] Müller M W, Schiffer H P, Hah C. Effect of circumferential grooves on the aerodynamic performance of an axial single-stage transonic compressor [C]. ASME paper, 2007, GT200727365, 115-124.

[3] Müller M W, Biela C, Schiffer $\mathrm{H}$ P, et al. Interaction of rotor and casing treatment flow in an axial single-stage transonic compressor with circumferential grooves [C]. ASME paper, 2008, GT2008-50135, 67-78.

[4] Bennington M A. Tip gap flow and casing treatments in an axial compressor [D]. South Bend: University of Notre Dame, 2009.

[5] Nan X, Ma N, Li J C, et al. Evaluation of the effectiveness of typical casing treatments for a low-speed compressor by an integral method [J]. Aerospace Science and Technology, May 2016, 52: 234-242.

[6] Vo H D, Tan C S, Greitzer E M. Criteria for spike initiated rotating stall [J]. ASME Journal of Turbomachinery, 2008, 130(1): 011023.
[7] Sakuma Y, Watanabe T, Himeno $T$, et al. Numerical analysis of flow in a transonic compressor with a single circumferential casing groove: influence of groove location and depth on flow instability [J]. ASME Journal of Turbomachinery, 2014, 136(3): 031017.

[8] Houghton T, Day I J. Enhancing the stability of subsonic compressors using casing grooves $[\mathrm{J}]$. ASME Journal of Turbomachinery, 2010, 133(2): 021007.

[9] Tan C S, Day I, Morris S, et al. Spike-type compressor stall inception, detection and control [J]. Annual Review of Fluid Mechanics, 2010, 42: 275-300.

[10] Day I J. Stall inception in axial flow compressors $[\mathrm{J}]$. ASME Journal of Turbomachinery, 1993, 115(1): 1-9.

[11] Wyer N, Farkas B, Desset J, et al. Experimental investigation of the steady and unsteady flow field in a single stage low pressure axial compressor with a circumferential groove casing treatment [C]. ASME paper, 2010, GT2010-23474, 487-499.

[12] Du J, Liu L, Nan X, et al. The dynamics of prestall process in an axial low-speed compressor with single circumferential casing groove [C]. ASME paper, 2013, GT2013-95432, V06CT42A033.

[13] Li J C, Lin F, Wang S C, et al. Extensive experimental study of circumferential single groove in an axial flow compressor [C]. ASME paper, 2014, GT2014-26859, V02DT44A036.

[14] Lin F, Chen J Y, Li M L. Experimental investigation of unsteady rotor tip flows in a high speed compressor throttled to stall [C]. ASME paper, 2002, GT2002-30360, 333-341.

[15] Lin F, Chen J Y, Li M L. Wavelet analysis of rotor-tip disturbances in an axial-flow compressor [J]. AIAA Journal of Propulsion and Power, 2004, 20(2): 319-334. 